\title{
Bulk Electroorganic Synthesis of Schiff Bases and Their Electrical Behaviour
}

\author{
Shreekanta S.A ${ }^{1}$, Venkatesh T. ${ }^{2 *}$ and Parameswara Naik.P ${ }^{1}$. \\ Murugendrappa. $\mathrm{N}^{3}$ \\ 1 Department of Chemistry, Sahyadri Science College, Shimoga,Karnataka,577 203, India. \\ 2Department of Chemistry, Kuvempu University, Shankaraghatta,577 451, Karnataka, India. \\ 3 Department of Electronics ,Kuvempu University, Shankaraghatta,577 451, Karnataka, India
}

\begin{abstract}
Schiff's bases 3a-c were synthesized by bulk electrochemical method and characterized by spectroscopic techniques. Electrochemical reduction of 3-nitro benzaldehyde(1a) and electrocatalysed condensation of 1a with 2a-c has been carried out at copper and zinc electrodes in the presence of potassium bromate as supporting electrolyte in water/methanol(80:20) solution. The electrochemical behaviour of compound $1 \mathrm{la}$ and $2 a-c$ were investigated in aqueous methanolic solution containing sodium sulphate \& potassium bromate as supporting electrolyte at copper cathode and zinc anode. The electrochemical was carried at the cell voltage of $23 \mathrm{~V}(3 \mathrm{a}), 32 \mathrm{~V}(3 \mathrm{~b}, 3 \mathrm{c})$ and highest current density required for the reduction of nitrogroup has been achieved.
\end{abstract}

Keywords: Electrochemical reduction,3-nitrobenzaldehyde,aminoaromatic compound, bulk synthesis, copper cathode, zinc anode.

\section{Introduction}

Schiff bases are the compounds having wide range of biological activities and industrial application. Schiff base reaction is used to protect $\mathrm{NH}_{2}$ group while nitration. The first reports of this kind of reaction have been published by Hugo Schiff in the 1860s. Theirafter Schiff bases have been intensively used as synthetic intermediates and as ligands for coordinating transition and inner transition metal ions. Schiff base ligands may contain a verity of substituent with different electron donating or electron with drawing groups, and therefore may have interesting chemical properties. Many researchers have shown interest in this class of organic compounds due to their biological activities, they have been found to posses the pharmacological activities such as antiviral, antibacterial, antifungal, antimalarial, anti-inflammatory, anticancerous. [1-8].

The importance of Schiff bases are mainly due to their physical properties in the crystalline state. There are O-H-----N or O----H-N type of intermolecular hydrogen bond and the related tautomerism exist between enol-imine forms in Aldimines compounds derived from the aromatic aldehydes having a hydroxyl group. The electron with drawing or electron releasing ability of the $\mathrm{N}$-substituent, their position and stereochemistry, as well as hydrogen bond donor-accepter properties, can stabilize one or another tautomer in the crystal. The transfer of proton from hydroxyl oxygen atom of the parent aldehyde to the imino nitrogen atom in crystal state causes remarkable changes in the distribution of pi electrons and such changes are closely connected with the physical properties in the crystalline Schiff bases, namely thermochromism and phototropism. salicylaldimines are thermodynamic compounds. It was established that these two effects are conformation-dependent. Non-planar molecules can exhibit photo-chromism, while planar molecules of this type Schiff bases exhibit thermo-chromism[1]. In the present work amino group an electron releasing group was introduced while preparing the electro-catalyzed Schiff bases. This was done by reducing nitro-group at the cathode with minimum time and selective reduction. Presence of azomethine group is responsible for antimicrobial activity, which can be altered depending upon the type of substituent on the aromatic rings. The metal complexes of $\mathrm{N}$ and $\mathrm{S}$ chelating ligands have attracted considerable attention because of their interesting physicochemical properties and pronounced biological activities. They are capable of forming complexes with transition metals. The permeability of drugs is increased through the formation of chelates invivo and the drug action is increased due to penetration of the drug into the site of action. Schiff bases are important intermediates in a number of enzymatic reactions involving interaction of an amino or a carbonyl group of the substrate. The most important reaction in biochemical processes involves condensation of a primary amine in an enzyme which is a lysine residue, with a carbonyl group of the substrate to form an imine.

The biological activity and industrial applications of Schiff bases makes their investigations very interesting. In this direction, Schiff bases were synthesized by conventional method by many workers. The time required for the synthesis of Schiff bases in conventional method was found to be 8-10 hours. However, our studies 2 revealed that the time required for the synthesis of these compounds was 30-50 minutes. 
The spectroscopic study of Schiff bases derived from amino benzoic acid with bromo benzaldehyde and the characterization of Schiff base containing an azogroup have been reported by others [5]. The decrease in bond order in azomethine and decrease in electro-negativity of azomethine group have been reported by many researchers $[1,2]$. The electro-chemical methods such as electrocarboxylation been reported by others. The decrease in bond order in azomethine and decrease in electro negativity of azomethine group have been reported by many researchers [1]. The electrochemical methods such as electrocarboxylation, electro reductive coupling, electrocyclisation have been reported by many researchers [3-5], Polymers incorporating ethylated Schiff bases are found to be semi conductive. The electrochemical oxidation very often parallels the cytochrome p450 catalyzed oxidation in liver microsomes [1-4].

In the aim of investigating synthesis of amino derivatives of Schiff bases derived from, $2 a, 2 b$ and $2 c$ with 1a, in aqueous methanolic solution in 1a with2a at copper cathode and zinc anode, aqueous acetic $\mathrm{acid} /$ methanol in 1a, $2 \mathrm{~b}$ and aqueous ethanol in 1a, $2 \mathrm{c}$ at copper cathode and platinum/zinc anode in presence of potassium bromate as supporting electrolyte (scheme) was carried out by electrochemical method.

We investigated the formation imine group, $\mathrm{CH}=\mathrm{N}$ with $\mathrm{NH}_{2}$ in one of its aromatic ring by electrochemical method in undivided cell.The $\mathrm{NH}_{2}$ group may be converted into hydroxyl group.

The electron with drawing or electron releasing ability of the N-substituent, their position and stereochemistry, as well as hydrogen bond donor-accepter properties, can stabilize one or another tautomer in the crystal. The transfer of proton from hydroxyl oxygen atom of the parent aldehyde to the imino nitrogen atom in crystal state causes remarkable changes in the distribution of pi electrons and such changes are closely connected with the physical properties in the crystalline Schiff bases, namely thermochromism and phototropism. It was established that these two effects are conformation-dependent.Non-planar molecules can exhibit photo-chromism, while planar molecules of this type Schiff bases exhibit thermo-chromism[1]. The presence an electron releasing group such as aminogroup on the aromatic ring of schiff's base enhances physical as well as the biological properties of schiff's bases The Presence of azomethine group is responsible for antimicrobial activity, which can be altered depending upon the type of substituent on the aromatic rings. The metal complexes of $\mathrm{N}$ and $\mathrm{S}$ chelating ligands have attracted considerable attention because of their interesting physicochemical properties and pronounced biological activities.

According to our experimental results, it seems that the electrochemical reactions of $1 \mathrm{a}$ with $2 \mathrm{c}$ is faster than the reaction between $1 \mathrm{a}$ with $2 \mathrm{~b}$, in turn it is faster than the reaction between $1 \mathrm{a}$ and $2 \mathrm{a}$,leading to the product 3a-c. The slow reaction between 1a and $2 \mathrm{a}$ in scheme is due to the presence of an electron withdrawing group. During the reaction the nitro group of $1 \mathrm{a}$ was reduced to amino group without disturbing other functional group. In this connection [1], $\mathrm{H}^{1} \mathrm{NMR}$ spectrum of the obtained product 3a indicates one singlet peak for protons in the imine group $(8.265 \mathrm{ppm})$. The IR spectra also indicate the presence of $\mathrm{C}=\mathrm{N}$ group $\left(1611 \mathrm{~cm}^{-1}\right)$. The structure of the product was also confirmed by $\mathrm{CHN}$ analysis. The spectral data also indicated the presence of imine group in the products $3 \mathrm{a}-\mathrm{c}$ the spectral date of products in scheme were given in the experimental section.

The obvious advantages of the current method over previously known methods are; more detail about spectral analysis data is described in the experimental section. From the point of view of green chemistry, the use of electro organic synthesis method has some important advantages. It is a clean synthesis which involves the use of electricity as energy instead of prolonged heating and use of aqueous media (80\% water) instead of organic solvents. It seems to eco friendly, one step reaction and easy to scale up.

Apparatus and reagents.

\section{Experimental Section}

The reaction equipments were as follows, the glassware electrolytic cell equipped with zinc plate anode $\left(3 \times \mathbf{c m}^{2}\right)$ and copper plate $\left(3 \times 4 \mathbf{c m}^{2}\right)$ cathode, all chemicals were reagent grade materials. These chemicals were used without further purification.

\section{Scheme}
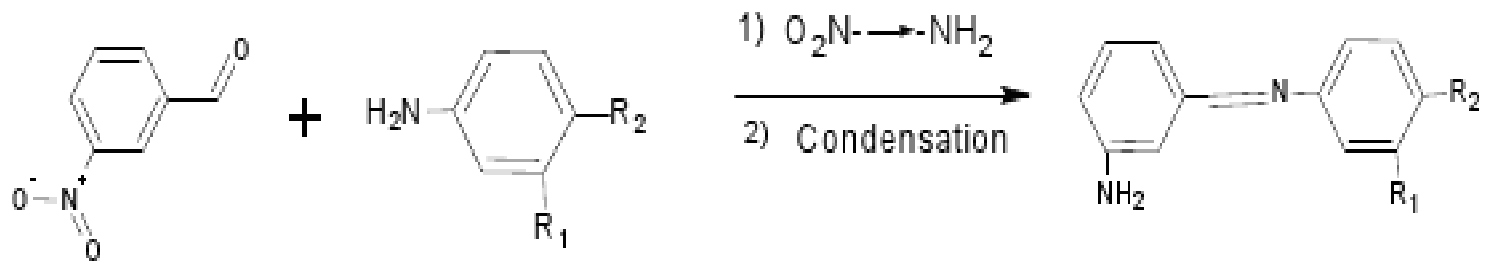


\begin{tabular}{|c|c|c|c|}
\hline $\mathbf{1}$ & \multicolumn{2}{|c|}{$\mathbf{2}$} & $\mathbf{3}$ \\
\hline & $\mathrm{R}_{1}$ & $\mathrm{R}_{2}$ & $\begin{array}{c}\text { Isolated } \\
\text { Yield }\end{array}$ \\
\hline $\mathbf{a}$ & $\mathrm{COOH}$ & $\mathrm{H}$ & $85 \%$ \\
\hline $\mathbf{b}$ & $\mathrm{H}$ & $\mathrm{H}$ & $90 \%$ \\
\hline $\mathbf{c}$ & $\mathrm{H}$ & $\mathrm{CH}_{3}$ & $90 \%$ \\
\hline
\end{tabular}

Electroorganic synthesis of 3a-c.

3a. In a typical procedure, a solution of water: methanol(80:20) containing $1 \mathrm{mmol}$ of meta nitrobenzaldehyde (1a) and $1 \mathrm{mmol}$ meta aminobenzoic acid (2a), 0.8g supporting electrolyte potassiumbromate was electrolyzed in an undivided cell equipped with a copper cathode $\left(3 \times 4 \mathrm{~cm}^{2}\right)$ and zinc anode $\left(3 \times 4 \mathrm{~cm}^{2}\right)$ at a constant cell voltage of $23 \mathrm{~V}$, at $25^{\circ} \mathrm{C}$. The contents were stirred using magnetic stirrer. The electrolysis was stopped when pale brown compound obtained. The progress of the reaction was monitored by TLC (pet ether: ethyl acetate, (1:1). The product 3a was extracted by dry ether and was recrystalised by dry ether. After recrystallisation, products were characterized by IR, ${ }^{1} \mathrm{HNMR}$, CHN analysis. The isolated yields of 3a after crystallization are reported in the scheme

3-(3-aminobezilidine amino) benzoic acid (3a) $\left(\mathrm{C}_{14} \mathrm{H}_{12} \mathrm{~N}_{2} \mathrm{O}_{2}\right)$, mp 78-80 ${ }^{0} \mathrm{C}$.

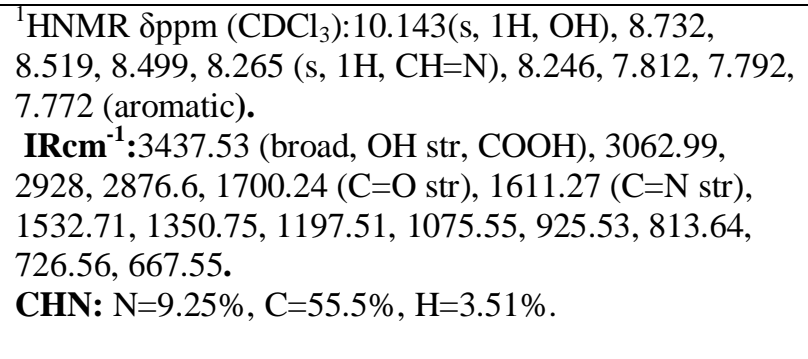

3b. In a typical procedure, a solution of water: acetic acid(80:20) containing $1 \mathrm{mmol}$ of meta nitrobenzaldehyde (1a) and $1 \mathrm{mmol}$ aniline (2b) supporting electrolyte potassium bromate was electrolysed in an undivided cell equipped with a copper cathode $\left(3 \times 4 \mathrm{~cm}^{2}\right)$ and zinc anode $\left(3 \times 4 \mathrm{~cm}^{2}\right)$ at a constant cell voltage of $32 \mathrm{~V}$. At $25^{\circ} \mathrm{C}$. The contents were stirred using magnetic stirrer. The electrolysis was stopped when reddish brown compound obtained. The progress of the reaction was monitored by TLC. The product $3 \mathrm{~b}$ was extracted by dry ether. After recrystallisation, products were characterized by IR, ${ }^{1 \mathrm{HNMR}}, \mathrm{CHN}$ analysis. The isolated yields of $3 \mathrm{~b}$ after crystallization are reported in the scheme.

$\mathrm{N}$-(3-aminobezilidine) aniline.3b. $\left.\mathrm{C}_{13} \mathrm{H}_{12} \mathrm{~N}_{2}\right)$

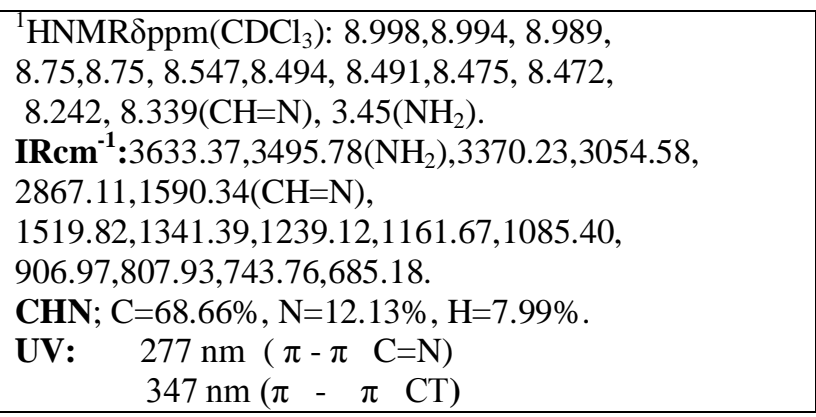

procedure, a solution of containing $1 \mathrm{mmol}$ of

water: methanol $(80: 20)$

meta nitrobenzaldehyde (1a) and $1 \mathrm{mmol}$ para toluidine (2c), $0.8 \mathrm{~g}$ of supporting electrolyte potassium bromate, $2 \mathrm{~g}$ $\mathrm{NaOH}$ was electrolyzed in an undivided cell equipped with a copper cathode $(1 \times 0.5 \times 4 \mathrm{~cm})$ and zinc anode at a constant cell voltage of $32 \mathrm{~V}$, at $25^{\circ} \mathrm{C}$. The contents were stirred using magnetic stirrer. The electrolysis was stopped when light yellow compound obtained. The progress of the reaction was monitored by TLC. The product $3 \mathrm{c}$ was extracted by dry ether. After recrystallisation, product was characterized by IR, ${ }^{1} \mathrm{HNMR}, \mathrm{CHN}$ analysis. The isolated yields of $3 \mathrm{c}$ after crystallization are reported in the scheme.

$\mathrm{N}$-\{(Z)-(3-aminophenyl)methylidene $\}-4$-methylaniline.3c.mp $80-82^{\circ} \mathrm{C}$

FTIRcm $^{-1}$;

$3421,3094,2870,1620,1526,1443,1345,1265,1073,957,814$

727,672 . 
Fig. 1 and Fig, $2 \& 3,4$ as Supporting Information Available; Copies of IR, 1HNMR, CHN of compounds 3a-c. $3 \mathrm{a}=\mathrm{S}_{7}, \mathbf{3 b}=\mathbf{S 8}$ and $3 \mathrm{c}=\mathrm{S}_{15}$

Mechanism:

The electrochemical conversions of 1a into 3a-c in scheme involve the following mechanism.

The mechanism of reduction of nitro derivatives in various solvents as mentioned in the experimental section proceeds with the formation of hydroxyl amino compounds. The hydroxylamine reduced further into amino derivative in two steps.

$$
-\mathrm{NO}_{2} \stackrel{2 \mathrm{e}-, 2 \mathrm{H}^{+}}{\longrightarrow}-\mathrm{NHOH} \stackrel{2 \mathrm{e}-, 2 \mathrm{H}+}{\longrightarrow}-\mathrm{NH}_{2}
$$

The reaction of 1a with 2a in scheme can be explained as follows. The aldehyde group condensed with amine group of the compounds and loses a molecule of water forming an imine compound. The process was catalyzed by both anode and cathode.

$$
-\mathrm{CHO}+\mathrm{NH}_{2} \longrightarrow \mathrm{CH}=\mathrm{N}-+\mathrm{H}_{2} \mathrm{O}
$$

The electro chemical behavior of the compound 3a-c in scheme was studied in the present work. The electrochemical reactions of $1 \mathrm{a}$ with $2 \mathrm{a}, 2 \mathrm{band} 2 \mathrm{c}$ depends on current densities. Therefore current densities were increased by adding the supporting electrolytes. The high yield was found at the current density $0.066 \mathrm{~A} / \mathrm{cm}^{2}$ This current density was produced by adding $2 \mathrm{~g}$ of sodium sulphate as shown in table 1 .

Table.1:- 3mmol $p$-toluidine and $3 \mathrm{mmol} m$-nitrobenzaldehyde, Room temperature $\left(27^{0} \mathrm{C}\right)$,

The graphics of this table

\begin{tabular}{|c|c|c|}
\hline $\begin{array}{c}\text { Amount of } \\
\text { potassiumbromate } \\
\text { in gm }\end{array}$ & $\begin{array}{c}\text { Current } \\
\text { density }\end{array}$ & $\begin{array}{c}\text { Yield } \\
\text { in \% }\end{array}$ \\
\hline 0 & 0 & - \\
\hline 0.1 & 0.008 & 60 \\
\hline 0.4 & 0.0033 & 62 \\
\hline 0.8 & 0.005 & 65 \\
\hline 1.2 & 0.05 & 68 \\
\hline 1.6 & 0.066 & 70 \\
\hline 2.0 & 0.066 & 70 \\
\hline
\end{tabular}

$\mathrm{Cu}$ cathode, $\mathrm{Zn}$ anode, $20 \mathrm{~cm} 3$ methanol $+100 \mathrm{~cm}^{3}$ water. The sodium sulphate was used as a supporting electrolyte, as the concentration of electrolyte increases the electron densities was also increased. The organic compound must at least partially soluble in water. Therefore in the present work the compound was dissolved in the mixture of water and methanol. Turbidity was produced while preparing the electrolytic solution. This was avoided by using the mixture of methanol and water in the ratio 20:80. The concentration of sodium hydroxide also varied to produce the high current density in the table-2.The sodium hydroxide concentration was increased, so that the $\mathrm{pH}$ of the solution increases above nine. This condition was found to be suitable for reduction. As the concentration of $\mathrm{NaOH}$ increases, the current density also increases. The volume of water gradually increased in the table-3.As volume of water increases, the current densities increases, but at a certain stage, if volume of water exceeds when compared to organic solvent, turbidity produces, and then current densities drops to minimum.Threfore the ratio of water to organic solvent was maintained during the electro chemical reaction.

Table-2:- 3mmol $p$-toluidine and 3mmol $m$-nitrobenzaldehyde. Room temperature $\left(27^{0} \mathrm{C}\right), \mathrm{Zn}$ Cathode, pt anode, $20 \mathrm{~cm} 3$ methanol, $1.6 \mathrm{~g}$ sodiumsulphate.

\begin{tabular}{|c|c|c|}
\hline $\begin{array}{c}\text { Amount of sodium } \\
\text { hydroxide in gm }\end{array}$ & Current density & Yield in \% \\
\hline 0 & 0.066 & 70 \\
\hline 0.1 & 0.008 & 70 \\
\hline 0.4 & 0.0125 & 78 \\
\hline 0.8 & 0.0166 & 80 \\
\hline 1.2 & 0.01875 & 85 \\
\hline 1.6 & 0.02083 & 89 \\
\hline 2.0 & 0.0233 & 90 \\
\hline
\end{tabular}


The graphics of this table is shown in fig, 6

\section{Result:-}

It is demonstrated that amino derivatives of Schiff bases 3a-c in the scheme produced by the electrochemically driven reduction of nitro compounds $1 \mathrm{a}$, followed by electcatalysed condensation of the amino compounds with aldehyde $2 \mathrm{a}-\mathrm{c}$ produce the product $3 \mathrm{a}-\mathrm{c}$ via an electrochemical path way. The electrochemical synthesis of 3a-c has been successfully performed in one pot in ambient conditions and in an undivided cell using an environmentally friendly method with high atom economy. The compound 1a shows electro reduction behavior in presence of potassium bromate as supporting electrolyte. All compounds were obtained in good yield.

\section{References}

[1] Anita Blagus; Dominik Cincic, Tomislav, Branko Kaitner, Vladimir Stilinovic, Maced. J. Chem.eng. 2010.29 .117 - 138

[2] Neelakantan; M.A, Esakkiammal, M,Mariappan, S.S. Dharmaraja, J. Jeyakumar, T. Indian. J Pharm. Sci. 2010 , 72 , 216

[3] Shelar Mahendra Devidas,Shujat Hussain Quadri,Suresh Arjun Kamble,Faozia Mansoor Syed and Dipak.y.Vyavhare.J.Chem.Pharm.Res.,2011,3.489-495.

[4] Davood Nematollahi,Esmail Tammari.J.Org.Chem.2005.70.7769-7772.

[5] Abdullah Hussein Kshash.j.chem.2011.2.2010

[6] Walter Lob.; Lorenz, A. M. electrochemistry of organic compounds, $3^{\text {rd }}$ ed.; John Wiley and Sons. Chapman and Hall, Limited; London. 1906.

[7] Davood Nematollahi.; Hassan Goodazi. J Org. Chem. 2002.67.5036.

[8] Padmini, V. Arc. app. sci. Res. 2010. 2. 356356.

[9] Manish, K.; Rawal.; Amit Sahu.; Rakshit Ameta.; Sharma,V.K.; Pinki, B. Panjabi. Int J. Chem. Tech .Res. coden. USA.2009. 1.1182 .

[10] Soonki Won, Wanjoong Kim,; Hongbum Kim.; Bull. Korean Chem. Soc. 2006, 27, 2, 195.

[11] Santosh Kumar, Nirjan M.S., Chaluvaraju K C., Jamakhandi C M and Dayananda Kadadevar ; JCPR, 2010 ; 01:39-42

[12] Ajay Kumar D, Julkarni D, Sangamesh A, Patil, Prema S Badami, Int. J. Electrochem, 2009, 4, 117-729

[13] S.A. Abd, El-Maksoud, Int. J. Electrochem, Sci. 2008, 3, 528-555

[14] A.P. Mishra and Neha Sharma, J. Ind. Council C hem, 2009, 26, 125-129

[15] Percio Augusto, Mardini Farias and Margarida Bethlem Rodriguses Bastos, Int. J. ELectrochem, 2009, 4, 458-470

[16] R.Sarganesh,K.KBalasubramaniam, and S Venkatachalam, Bull. Electrochem., 1990, 6, 515;

[17] C.J.Patel, A.S.Madhov, G. Ramachandraiah, and D.N. Vyes,Bull.Electrochem.,1995,11,159.

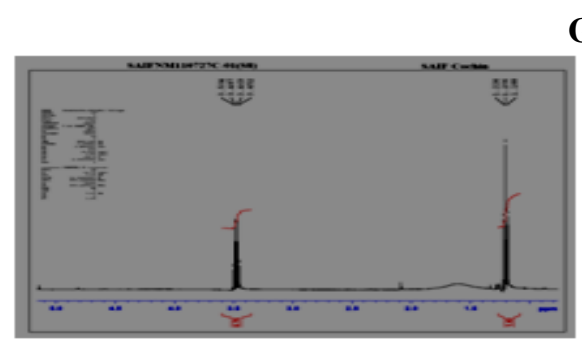

\section{Graphical figures}
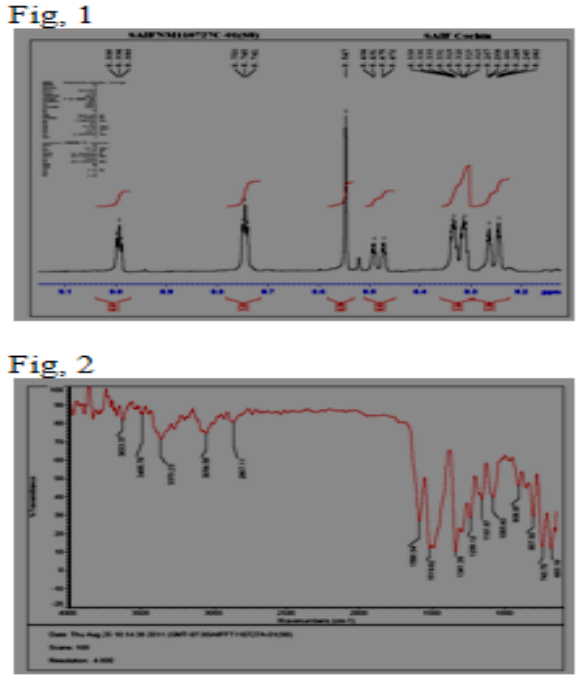

Fig, 3

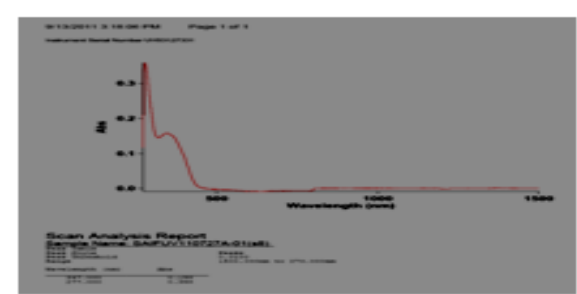

Fig, 4

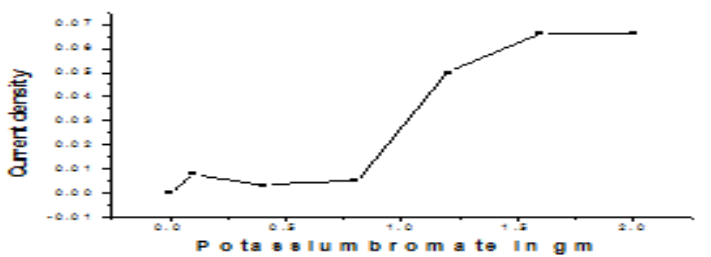

Figs, 5

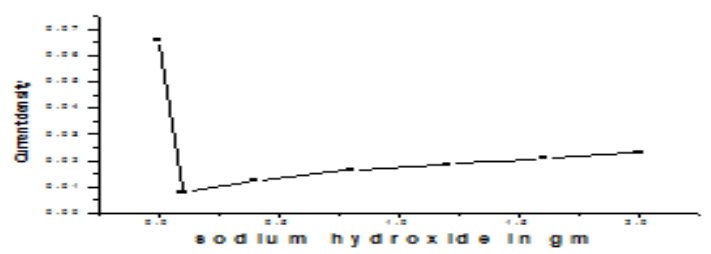

Fig, 6 